\title{
Preview of the June issue featuring literature reviews of MCDA and articles authored by students
}

\author{
Zachary A. Collier $^{1} \cdot$ James H. Lambert $^{1} \cdot$ Igor Linkov $^{2}$
}

Published online: 13 May 2017

(C) Springer Science+Business Media New York 2017

This quarter's issue of Environment Systems \& Decisions features two special research highlights. First, two review papers investigate historical and future trends in the application of multicriteria decision analysis (MCDA) in the academic literature. These reviews investigate different aspects of MCDA in research and in practice. Cegan et al. (2017) conduct a literature search aided by text mining analysis to explore trends in how decision-making approaches have been applied in the environmental sciences. Aspects such as methodologies (e.g., AHP, TOPSIS, MAUT, MAVT, Outranking), environmental applications (e.g., water, air, energy), and other relevant factors were documented and synthesized. Complementing this work, Kurth et al. (2017) documented trends in how MCDA has been used specifically within US government agencies. Together, these papers provide an in-depth assessment of the past, present, and future of MCDA research.

The second collection of articles highlights the work of student authors. While the topics vary across these three papers, the common thread is that all of the first authors are students. In the first paper, Hinrichs et al. (2017) discuss the challenges of collaboration in interdisciplinary team science settings and provide several recommendations for fostering innovation. Next, McKay et al. (2017) developed

Igor Linkov

igor.linkov@usace.army.mil

Zachary A. Collier

zac4nf@virginia.edu

James H. Lambert

lambert@virginia.edu

University of Virginia, Charlottesville, VA, USA

2 US Army Engineer Research and Development Center, Concord, MA, USA a tool to quantify metrics of governance quality for socioecological systems, drawing from a wide variety of fields such as ecology and business. Finally, De Nardo et al. (2017) conducted structured interviews to investigate the relationship between perceptions of different pro-environmental behaviors and social status.

Finally, the issue concludes with an assortment of general submissions that span research domains and application areas. Sardar et al. (2017) present an integrative method combining various numerical analyses with GIS and remote sensing in an effort to estimate solar downward shortwave radiation, which has implications for agriculture, climatology, and other fields. McCurdy and Travis (2017) developed a method to examine the effects of different climate change adaptation strategies to the cost efficiency and service level of drainage infrastructure. Haywood et al. (2017), in a conceptual paper, explore the relationships between enterprise risk management and systems thinking and identify potentials for tools from the systems modeling domain which can be applied for effective risk management.

Upcoming special issues of Environment Systems \& Decisions include topics of Food Security (planned for late 2017) and Resilience in Socio-Technical Systems (planned for early 2018).

\section{References}

Cegan JC, Filion AM, Keisler JM, Linkov I (2017) Trends and applications of multi-criteria decision analysis in environmental sciences: literature review. Environ Syst Decis. doi:10.1007/ s10669-017-9642-9

De Nardo M, Brooks JS, Klinsky S, Wilson C (2017) Social signals and sustainability: ambiguity about motivations can affect status 
perceptions of efficiency and curtailment behaviors. Environ Syst Decis. doi:10.1007/s10669-017-9624-y

Haywood LK, Forsyth GG, de Lange WJ, Trotter DH (2017) Contextualising risk within enterprise risk management through the application of systems thinking. Environ Syst Decis. doi:10. 1007/s10669-017-9627-8

Hinrichs MM, Seager TP, Tracy SJ, Hannah MA (2017) Innovation in the Knowledge Age: implications for collaborative science. Environ Syst Decis. doi:10.1007/s10669-016-9610-9

Kurth MH, Larkin S, Keisler JM, Linkov I (2017) Trends and applications of multi-criteria decision analysis: use in government agencies. Environ Syst Decis. doi:10.1007/s10669-017-9644-7
McCurdy AD, Travis WR (2017) Simulated climate adaptation in stormwater systems: evaluating the efficiency of adaptation strategies. Environ Syst Decis. doi:10.1007/s10669-017-9631-z

McKay PA, Vogt CA, Olabisi LS (2017) Development and testing a diagnostic capacity tool for improving socio-ecological system governance. Environ Syst Decis. doi:10.1007/s10669-016-9611-8

Sardar T, Xu A, Raziq A (2017) Downward shortwave radiation estimation and spatial assessment on sites over complex terrain applying integrative approach of MTCLIM-XL, interpolation, RS and GIS. Environ Syst Decis. doi:10.1007/s10669-017-9637-6 